\title{
Effect of Mechanical Ventilation During Cardiopulmonary Bypass On End-Expiratory Lung Volume in The Perioperative Period of Cardiac Surgery
}

\author{
Lea Trancart \\ CHU Rouen: Centre Hospitalier Universitaire de Rouen \\ Nathalie Rey \\ CHU Rouen: Centre Hospitalier Universitaire de Rouen \\ Vincent Scherrer \\ CHU Rouen: Centre Hospitalier Universitaire de Rouen \\ Véronique Wurtz \\ CHU Rouen: Centre Hospitalier Universitaire de Rouen \\ Fabrice Bauer \\ CHU Rouen: Centre Hospitalier Universitaire de Rouen \\ Chadi Aludaat \\ CHU Rouen: Centre Hospitalier Universitaire de Rouen \\ Zoe Demailly \\ CHU Rouen: Centre Hospitalier Universitaire de Rouen \\ Jean Selim \\ CHU Rouen: Centre Hospitalier Universitaire de Rouen \\ Vincent Compère \\ CHU Rouen: Centre Hospitalier Universitaire de Rouen \\ Thomas Clavier \\ CHU Rouen: Centre Hospitalier Universitaire de Rouen \\ Emmanuel Besnier ( $\boldsymbol{\sim}$ besnier.emmanuel@gmail.com ) \\ CHU Rouen: Centre Hospitalier Universitaire de Rouen https://orcid.org/0000-0002-0267-0986
}

\section{Research article}

Keywords: Ventilation during cardiopulmonary bypass, End Expiratory Lung Volume, Functional Residual Capacity, Cardiac Surgery

Posted Date: November 9th, 2021

DOI: https://doi.org/10.21203/rs.3.rs-1039929/v1

License: (c) (1) This work is licensed under a Creative Commons Attribution 4.0 International License. Read Full License 


\section{Abstract \\ Background}

Many studies explored the impact of ventilation during cardiopulmonary bypass period. However, its effect on Functional residual capacity or End Expiratory Lung Volume (EELV) has not been specifically studied. Our objective was to compare the effect of two ventilation strategies during cardiopulmonary bypass (CPB) on EELV.

\section{Methods}

observational monocenter study in a tertiary teaching hospital. Adult patients undergoing on-pump cardiac surgery by sternotomy were included and ventilated on the GE Carescape R860® ventilator. Maintenance of ventilation during CPB was left to the discretion of the medical team, with division between "ventilated" and "non-ventilated" groups afterwards. Iterative per and postoperative measurements of EELV were carried out by nitrogen washin-washout technique.

\section{Results}

40 patients were included, 20 in each group. EELV was not significantly different between the ventilated versus non-ventilated groups at the end of surgery $(1796 \pm 586 \mathrm{ml}$ vs. $1844 \pm 524 \mathrm{ml} ; \mathrm{p}=1)$. No significant difference between the two groups was observed on oxygenation, duration of mechanical ventilation, need postoperative respiratory support, occurrence of pneumopathy and radiographic atelectasis.

\section{Conclusion}

Maintaining mechanical ventilation during CPB does not seem to allow a better preservation of EELV in our population.

\section{Introduction}

Pulmonary complications are the second most common cause of morbidity after cardiac surgery ${ }^{1}$. They lead to increased length of stay and mortality ${ }^{2,3}$. After cardiac surgery, alteration of respiratory function is observed during the immediate postoperative period and can last several days ${ }^{4}$. This is characterized by a decrease in lung volumes and especially in functional residual capacity (FRC), which can lead to atelectasis. A major mechanism for FRC reduction is related to the functional alteration of the diaphragm muscle, secondary to several mechanisms, including supine position, general anesthesia and direct surgical damages ${ }^{5}$. These mechanisms are particularly present during cardiac surgery because of the thoracic surgical approach, the duration of anesthesia and mechanical ventilation, but are not specific. One of the specificities of cardiac surgery is the use of Cardio-Pulmonary Bypass (CPB). During CPB, the inflation of pulmonary volumes, notably with the use of positive end-expiratory pressure (PEEP), can impede the surgeon, particularly during sternal access. Thus, up to $50 \%$ of some anesthetists systematically suspend mechanical ventilation during the CPB period to improve surgical comfort, the oxygenation and gas exchange being ensured by the heart-lung machine ${ }^{6,7}$. In recent years, numerous studies have been carried out to explore the relevance of maintaining (or not) the mechanical ventilation during $\mathrm{CPB}$, however their results are conflicting and have not led to any guidelines on the subject ${ }^{8-10}$. Indeed, a close relationship has been observed between nonventilated lung volumes and the degree of hypoxemia, shunt and pulmonary arterial hypertension in non-selected ICU patients ${ }^{11}$. Thus, it appears, at least from an intuitive point of view, that maintaining lung volumes, especially FRC, may be of major interest to prevent the formation of atelectasis and the subsequent pulmonary complications ${ }^{12,13}$.

Thus, we hypothesized that the maintenance of mechanical ventilation during CPB allows a better preservation of FRC. The main objective of our study was to explore the effect of mechanical ventilation during CPB on FRC. Secondary objectives were 
the impact of this ventilation strategy on oxygenation and pulmonary outcomes. We also investigated other parameters such as oxygenation, occurrence of pneumonia, atelectasis on chest X-ray, and use of intensive respiratory support.

\section{Materials And Methods Study characteristics}

We conducted an observational and monocenter study over a three-month period, from April to July 2020, in the cardiac surgical unit of a tertiary care teaching hospital. This study was approved by our local ethics committee (approval $n^{\circ}$ E202127). Because of the non-interventional design of the study and according to French law ${ }^{14}$, no written consent was required and no pre-registration on a public research website was realized. The perioperative strategy of ventilation for the non-CPB period of cardiac surgery was protocolized as a part of our local practices, as described hereafter before data acquisition.

\section{Population}

Patients were eligible if they underwent cardiac surgery by median sternotomy, with CPB and aortic clamping, under general anesthesia, with tracheal intubation and invasive mechanical ventilation using the Carescape R860® ventilator (General Electric Healthcare, USA) required for FRC estimation. Non-inclusion criteria were pregnancy, morbid obesity $(\mathrm{BMI}>40 \mathrm{~kg} / \mathrm{m} 2)$, chronic lung or neuromuscular disease, heart transplant procedure, cardiac assist device implantation, aortic dissection or surgery requiring a lateral thoracic approach. Our surgical team was constituted of 4 senior surgeons. Among them two used to perform surgery with the continuation of a minimal mechanical ventilation during CPB, and two request the interruption of the ventilation because of the related discomfort induced by the lung movements over the operated site. Thus, we have included all eligible consecutive patients in these two groups of surgeons and when the GE Carescape R860® ventilator was available (see below). If a prolonged interruption of ventilation ( $>5 \mathrm{~min}$ ) was required during $\mathrm{CPB}$, the patient was excluded from the analysis. Ventilation strategy has been previously standardized in our unit to homogenize practices among anesthetists (see section Intraoperative care and ventilation strategies).

\section{Intraoperative care and ventilation strategies}

After admission in operative room, patients were monitored as usual for high-risk general anesthesia: electrocardioscopy, pulse oximetry, invasive blood pressure using a radial $4 \mathrm{~F}$ catheter and central venous pressure through the jugular central venous catheter. Pre-oxygenation was carried out in a strict supine position $\left(0^{\circ}\right)$ using a $100 \% \mathrm{FiO}_{2}$ until obtaining an expired fraction of oxygen $\geq 90 \%$. Pre-oxygenation modality was left at the appreciation of the anesthetist between spontaneous ventilation or spontaneous ventilation with inspiratory support (4-10 $\mathrm{cmH}_{2} \mathrm{O}$ to achieve a $7 \mathrm{~mL} / \mathrm{kg}$ tidal volume, PEEP 4-6 cmH2O). Induction was then carried out by a combination of hypnotics (target-controlled infusion (TCl) of Propofol or Etomidate $0.4 \mathrm{mg} / \mathrm{kg}$ or Ketamine $2 \mathrm{mg} / \mathrm{kg}$ ), opioids ( $\mathrm{TCl}$ of Sufentanil or Remifentanil) and neuromuscular blocking agents (Cisatracurium 0.2 $\mathrm{mg} / \mathrm{kg}$ ). Anesthesia was then maintained by $\mathrm{TCl}$ of Propofol and of the same opioid that was used for induction.

Neuromuscular blockade was maintained by continuous administration of cisatracurium $0.1 \mathrm{mg} / \mathrm{kg} / \mathrm{h}$. Depth of anesthesia was assessed by BiSpectral Index Monitoring (BIS, Covidien, France) with a 40-60 target. Ventilation with a face mask was carried out with volume-controlled ventilation mode $\left(\mathrm{Vt} 7 \mathrm{ml} / \mathrm{kg}\right.$ of ideal body weight, respiratory rate $12-18 / \mathrm{min}, \mathrm{PEEP} 5 \mathrm{cmH}_{2} \mathrm{O}$ and $\mathrm{FiO}_{2} 100 \%$ ). Orotracheal intubation was then performed using direct laryngoscopy by a senior anesthetist. After intubation, mechanical ventilation was continued on the GE Carescape R860® ventilator. A standardized alveolar recruitment maneuver was then systematically performed, with controlled pressure ventilation mode and progressive increase in PEEP and insufflation pressures (see Supplementary File 1), with a maximum level of $20+12 \mathrm{cmH}_{2} \mathrm{O}$ maintained for 10 cycles before a progressive decrease. Ventilation was then carried out in volume-controlled mode (tidal volume $6-8 \mathrm{~mL} / \mathrm{kg}$, rate adjusted for $\mathrm{ETCO}_{2} 28-35 \mathrm{mmHg}, \mathrm{FiO} 2$ for SpO2 $\geq 95 \%$, PEEP 4-6 $\mathrm{cmH}_{2} \mathrm{O}$, I:E ratio 1:2). During sternal sawing, according to our habits, ventilation was suspended (<30 seconds), without PEEP and without disconnection from the ventilator, to limit the risk of pulmonary lesions. Maintenance of ventilation during CPB was left to the discretion of the medico-surgical team according to habits and surgical difficulties (see above). Patients were retrospectively categorized as "ventilation" and "non-ventilation" groups afterwards, according to the application of ventilation or not during CPB. The per-CPB ventilation consisted in a 2 
$\mathrm{mL} / \mathrm{kg}$ tidal volume, a $8 / \mathrm{min}$ respiratory rate, a $5 \mathrm{cmH}_{2} \mathrm{O}$ PEEP and a $40 \% \mathrm{FiO}_{2}$ with an inspiratory/expiratory ratio of $1: 1$. This small tidal volume ventilation was applied during the whole aortic clamping period. In the "non-ventilation group", no tidal volume and no PEEP was applied during the whole aortic clamping. Pre-CPB ventilation was then resumed before weaning from $\mathrm{CPB}$, with an initial $\mathrm{FiO}_{2}$ of $80 \%$ quickly adjusted to obtain $\mathrm{SpO}_{2} \geq 95 \%$.

During the procedure, the GE Carescape R860® ventilator coupled with the dedicated gas analyzer allowed continuous measurements of $\mathrm{N}_{2}$ and the subsequent measurement of End-Expiratory Lung Volume (EELV), which approximate FRC in the presence of PEEP, using the nitrogen "wash in-wash out" technique. It consists of a continuous measurement of changes in $\mathrm{O}_{2}$ and $\mathrm{CO}_{2}$ concentrations when the $\mathrm{FiO}_{2}$ changes and until equilibrium (washin), in order to calculate the dilution of $\mathrm{N}_{2}$ and deduce the EELV, which approximates FRC in the presence of PEEP. The EELV measurement is the average of this measurement (washin) and a second one, taken when the basic $\mathrm{FiO}_{2}$ is returned to baseline (washout) ${ }^{15}$. For each patient, we collected a baseline measurement after intubation and alveolar recruitment maneuver (T0), after chest-closure measurement (T1) and 1 hour after ICU admission (T2). Each measurement was performed after a stabilization period of at least 5 minutes with no change in ventilation parameters as recommended for EELV measurement. An arterial blood gas measure was realized at each time-point as usual (for design representation, see Supplementary File 2).

The transfer from operative room to intensive care unit (ICU) was performed using Monnal T60® transport ventilator. To avoid de-recruitment events during disconnections, circuit changes were performed after the intubation tube was clamped during an expiratory pause. In the ICU, these patients were ventilated with GE Carescape R860® ventilator, allowing monitoring of EELV.

All tidal volumes during this study were adjusted to the ideal body weight (IBW) calculated as IBW $=\mathrm{X}+0.91$ (height in $\mathrm{cm}$ 152.4) with $X=50$ for men and $X=45.5$ for women.

\section{Endpoints}

The primary endpoint was the value of EELV at the end of the procedure, after chest closure (T1).

The secondary end points were EELV 1 hour after ICU admission (T2), and different parameters of blood gases and pulmonary pressures at $\mathrm{T} 1$ and $\mathrm{T} 2: \mathrm{PaO}_{2}, \mathrm{PaO}_{2} / \mathrm{FiO}_{2}, \mathrm{PaCO}_{2}$, Driving Pressures (plateau pressure - PEEP) and static lung compliance (Cstat). We also explored the impact of the two strategies on pulmonary outcomes during ICU stay: use of respiratory support (non-invasive ventilation, high-flow nasal cannula or invasive mechanical ventilation for acute respiratory failure), and occurrence of pneumonia (clinically suspected or confirmed by bacteriological samples). We also explored the presence of atelectasis at day-one after surgery by systematic screening of chest X-ray, evaluated a posteriori by an expert radiologist blinded to the intraoperative strategy.

\section{Statistical analyses}

As this is a preliminary study with no data available from the literature, no calculation of the number of subjects was realized. Because of the physiologic endpoint, we estimated that 20 patients per group may be sufficient to demonstrate a difference.

The normality of the two groups was investigated by a D'Agostino test and data are presented as median with first and third quartiles or mean with standard deviations for quantitative variables, or percentage for qualitative variables. Comparisons of quantitative variables over time were carried out using a two-way ANOVA test for matched values considering time (T0, T1 and T2) and group (ventilated or non-ventilated). Holm-Sidak post-test for multiple comparisons was performed between the ventilated and non-ventilated groups at each time-point to adjust $p$ value to the number of comparisons. Comparisons of descriptive quantitative variables between the two groups were performed using a Student t-test or a Mann and Whitney twotailed test. Comparisons of qualitative variables were performed using an exact Fischer's test. An adjusted $p$ value strictly inferior to 0.05 was considered significant. Analyses were performed using GraphPad Prism v8.2 (GraphPad, USA).

\section{Results}


From April 10th to July 17th, 2020 we included a total of 40 patients (20/group). Demographic characteristics of the population are summarized in Table 1 with no difference concerning the various data. The use of positive pressure ventilation as a preoxygenation technique was similar in both groups $(n=13$ vs $12, p=1)$. There was no difference for duration of surgery (196 \pm 49 vs $196 \pm 64 \mathrm{~min}, p=0.9)$, CPB ( $86 \pm 41$ vs $81 \pm 34 \mathrm{~min}, p=0.7)$ or aortic clamping $(62 \pm 30$ vs $61 \pm 28 \mathrm{~min}, p=0.9)$. No difference was observed concerning the incidence of visualized pleural effraction during surgery $(13$ vs $14, p=1)$. Fluids infusion during the operative period was also similar ( $1700 \pm 340$ vs $1675 \pm 495 \mathrm{~mL}, \mathrm{p}=0.8$ ). Intraoperative ventilator settings in both groups are presented in Supplementary File 3. Per-CPB ventilator settings in the "ventilation" group were $2.6 \pm 0.6$ $\mathrm{mL} / \mathrm{kg}, 9 \pm 2 \mathrm{cycles} / \mathrm{min}, 5 \pm 1 \mathrm{cmH}_{2} \mathrm{O}$ PEEP and $40 \pm 10 \% \mathrm{FiO}_{2}$ and no interruption in the ventilation was observed.

Table 1

preoperative demographic characteristics of the population. BMI: Body Mass Index, COPD: Chronic Obstructive Pulmonary Disease, FRC: theoretical functional respiratory capacity estimated by the formula FRC $(L)=2.34 \times$ height $(m)+$ age $\times 0.01-1.09(20)$, LVEF: Left Ventricular Ejection Fraction

\begin{tabular}{|c|c|c|c|}
\hline & Ventilation & No Ventilation & $p=$ \\
\hline Age (years) & 70 [66-74] & $71[64-75]$ & 0.9 \\
\hline Male gender (n, \%) & $11(55 \%)$ & $16(80 \%)$ & 0.2 \\
\hline BMI $\left(\mathrm{kg} / \mathrm{m}^{2}\right)$ & $25.9 \pm 3.9$ & $26.7 \pm 4.2$ & 0.5 \\
\hline $\mathrm{BMI} \geq 30 \mathrm{~kg} / \mathrm{m}^{2}$ & $6(30 \%)$ & $7(35 \%)$ & 1 \\
\hline Hypertension & $14(70 \%)$ & $16(80 \%)$ & 0.7 \\
\hline Stroke & 1 & 3 & - \\
\hline Smoking status & $9(45 \%)$ & $8(40 \%)$ & 1 \\
\hline COPD & 1 & 2 & - \\
\hline Obstructive sleep apnea & 1 & 6 & - \\
\hline Preoperative Kidney disease & 4 & 6 & 0.7 \\
\hline Diabetes & 4 & 8 & 0.3 \\
\hline Euroscore II (\%) & $1.6[1.0-2.3]$ & $1.7[1.1-2.9]$ & 0.8 \\
\hline NYHA & $2 \pm 1$ & $2 \pm 1$ & 0.8 \\
\hline Preoperative LVEF (\%) & $65[51-71]$ & 66 [63-70] & 0.3 \\
\hline Type of surgery: & 11 & 6 & 0.08 \\
\hline Coronary artery bypass & 8 & 8 & \\
\hline Valvular surgery & 1 & 6 & \\
\hline \multicolumn{4}{|l|}{ Combined procedures } \\
\hline Theoretical FRC $(\mathrm{mL})$ & $3472 \pm 207$ & $3587 \pm 173$ & 0.06 \\
\hline Preoperative $\mathrm{SpO}_{2}(\%)$ & $95 \pm 7$ & $97 \pm 2$ & 0.1 \\
\hline
\end{tabular}

Results for the primary and secondary endpoints are presented in Table 2. Briefly, there was no difference concerning EELV at the end of surgery ( $1796 \pm 566$ vs $1844 \pm 524 \mathrm{~mL}, \mathrm{p}=0.6)$ but also at the other time-points, i.e at baseline (after orotracheal intubation) and 1 hour after ICU admission (2095 \pm 562 vs $2045 \pm 476 \mathrm{~mL}, \mathrm{p}=1)$. There was also no difference concerning static compliance (Cstat), driving pressure, blood oxygenation $\left(\mathrm{PaO}_{2} / \mathrm{FiO}_{2}\right)$ and $\mathrm{CO}_{2}$ partial pressure at the three time-points. The main outcomes in ICU were not different between "ventilation" and "no-ventilation" groups for SAPS-2 score (40 \pm 15 vs 
$36 \pm 8, p=0.3$ ), SOFA score at admission ( $4 \pm 2$ vs $4 \pm 1$ ), duration of postoperative mechanical ventilation ( $5.5 \pm 4.8$ vs $8.2 \pm$ $10.0 \mathrm{hrs}, \mathrm{p}=0.5$ ), incidence of $\mathrm{X}$-ray atelectasis ( $7 \mathrm{vs} 8, \mathrm{p}=1$ ), use of high-flow nasal cannula or non-invasive ventilation support ( 2 vs $0, p=1$ ) or pneumonia ( 2 vs $0, p=0.5)$.

Table 2

Results for physiologic parameters in "ventilation" and "no-ventilation" CPB strategies at the three time-points T0 (baseline after orotracheal intubation), T1 (end of surgery) and T2 (1 hour after ICU admission). EELV: End Expiratory Lung Volumes; Cstat: static compliance.

\begin{tabular}{|c|c|c|c|c|c|c|c|c|c|}
\hline & TO & & & $\mathrm{T} 1$ & & & $\mathrm{~T} 2$ & & \\
\hline & ventilation & $\begin{array}{l}\text { no- } \\
\text { ventilation }\end{array}$ & $\begin{array}{l}\mathrm{p} \\
\text { value }\end{array}$ & ventilation & $\begin{array}{l}\text { no- } \\
\text { ventilation }\end{array}$ & $\begin{array}{l}\mathrm{p} \\
\text { value }\end{array}$ & ventilation & $\begin{array}{l}\text { no- } \\
\text { ventilation }\end{array}$ & $\begin{array}{l}\mathrm{p} \\
\text { value }\end{array}$ \\
\hline $\mathrm{EELV}(\mathrm{mL})$ & $\begin{array}{l}2206 \pm \\
790\end{array}$ & $\begin{array}{l}1966 \pm \\
482\end{array}$ & 0.6 & $\begin{array}{l}1796 \pm \\
566\end{array}$ & $\begin{array}{l}1844 \pm \\
524\end{array}$ & 1 & $\begin{array}{l}2095 \pm \\
562\end{array}$ & $\begin{array}{l}2045 \pm \\
476\end{array}$ & 1 \\
\hline $\begin{array}{l}\text { Cstat } \\
\left(\mathrm{mL} / \mathrm{cmH}_{2} \mathrm{O}\right)\end{array}$ & $73 \pm 35$ & $79 \pm 25$ & 0.9 & $71 \pm 27$ & $66 \pm 16$ & 0.9 & $57 \pm 15$ & $58 \pm 14$ & 1 \\
\hline $\begin{array}{l}\text { Driving } \\
\text { Pressure } \\
\left(\mathrm{cmH}_{2} \mathrm{O}\right)\end{array}$ & $8 \pm 3$ & $7 \pm 2$ & 0.6 & $7 \pm 1$ & $8 \pm 1$ & 0.3 & $9 \pm 3$ & $9 \pm 3$ & 1 \\
\hline $\begin{array}{l}\mathrm{PaO} 2 / \mathrm{FiO} \\
(\mathrm{mmHg})\end{array}$ & $381 \pm 156$ & $398 \pm 137$ & 1 & $339 \pm 149$ & $304 \pm 131$ & 0.8 & $324 \pm 115$ & $329 \pm 124$ & 1 \\
\hline $\begin{array}{l}\mathrm{PaCO} 2 \\
(\mathrm{mmHg})\end{array}$ & $40 \pm 4$ & $38 \pm 5$ & 0.6 & $37 \pm 4$ & $37 \pm 4$ & 1 & $39 \pm 4$ & $39 \pm 4$ & 1 \\
\hline
\end{tabular}

\section{Discussion}

Maintaining mechanical ventilation during CPB was not associated in our study with better preservation of EELV. Despite less accurate than chest tomography imaging, $\mathrm{N}_{2}$ washin-washout techniques have been widely studied and showed good correlations and/or agreements with pulmonary volumes, allowing their use at the bench side in various settings, including critical cares ${ }^{16-18}$. We can therefore strongly believe that post-operative FRC was not modified by per-CPB ventilation in our cohort.

This study approaches the effect of per-CPB ventilation from an original angle. Previous studies have focused on its effect on oxygenation, postoperative respiratory complications or systemic inflammation ${ }^{8,10,19}$. To date there is no study specifically studying the impact of maintaining mechanical ventilation per-CPB on lung volumes during adult cardiac surgery, whereas most of the modern ventilation strategies in ICU or operative room are based on this concept of "lung protection", using reduced tidal volume, sufficient PEEP and recruitment maneuvers to prevent lung collapse 20,21 .

Different studies have investigated the effect of maintaining ventilation during CPB on different clinical or biological parameters. A meta-analysis of 15 randomized trials conducted between 1993 and 2016, explored mechanical ventilation or continuous positive airway pressure during CPB on the evolution of the alveolar-arterial oxygen gradient, oxygenation, duration of mechanical ventilation and length of stay ${ }^{22}$. No significant difference was found with regard to the criteria studied. However, a significant improvement of the $\mathrm{PaO}_{2} / \mathrm{FiO}_{2}$ ratio in favor of maintaining ventilation can be noted in one of the 4 trials studying this parameter, as well as a decrease of the alveolo-arterial oxygen gradient in 2 trials. One of the limits of this meta-analysis was the heterogeneity of ventilation parameters among studies. More recently, the PROVECS study compared the effect of two ventilation strategies on the occurrence of postoperative respiratory complications. A total of 494 patients was randomized between "conventional" ventilation strategy and "protective" strategy, which included the maintenance of ventilation during CPB but also higher intraoperative PEEP and recruitment maneuvers. No significant difference was found in the occurrence of postoperative pulmonary complications, hypoxemia or use of respiratory support. 
Different physiological hypotheses may explain the lack of effect in our study. The duration of CPB was limited with a mean duration of $60 \mathrm{~min}$, and thus we can hypothesize that this period was too short to induce a significant difference in FRC. Another element may be the non-selected nature of the included patients, notably with the absence of patients with pulmonary underlying conditions. Indeed, in the IMPROVE study which demonstrated a benefit of protective ventilation in major abdominal surgery, the included patients presented a preoperative risk index for pulmonary complications of more than two ${ }^{20}$. Thus, it is possible that the association of a short duration of aortic clamping and the absence of preoperative risk factors may have mitigated the potential beneficial effects of per-CPB ventilation strategy. Another hypothesis concerns the choice of mechanical ventilation parameters during CPB. In our study, the ventilation was maintained with low tidal volume (Vt $2.6 \pm$ $0.6 \mathrm{ml} / \mathrm{kg}$ of IBW), which may be close to the theoretical dead-space volume $(\approx 1.5 \mathrm{~mL} / \mathrm{kg})$, and thus insufficient to keep the alveoli opened. However, higher volumes hamper the surgeon, potentially decreasing the quality of surgical exposure. Another element, specific to cardiac surgery under CPB with aortic clamping, is the exclusion of pulmonary vascularization. Indeed, experimental studies suggested that pulmonary vascularization is involved in maintaining the mechanical and architectural properties of the lung. Gibney et al, observed in animal models a decrease in pulmonary compliance if vascularization is stopped $^{23}$. Thus, the mere maintenance of mechanical ventilation may not be able to counteract this "ischemic" closure of the lung.

Concerning the secondary endpoints, maintaining mechanical ventilation during CPB does not appear to be associated with any significant effect in our population. Thus, we found no significant difference either on clinical criteria (occurrence of pneumonia, duration of invasive mechanical ventilation, non-invasive ventilation or high flow oxygen therapy) or other criteria (oxygenation parameters, driving pressure, static compliance, postoperative atelectasis). Nevertheless, the small size of the population does not allow us to definitively conclude on this point.

Some limitations of our study must be discussed. First, the lack of randomization limits the impact of conclusion, despite great similarities between groups, notably concerning euroscore-2, obesity, age... Even if we observed a trend to an unbalance concerning the type of surgery, with more combined procedures in the not-ventilated group, this difference was not significant. Furthermore, if we suggest that the complexity of the procedure may alter pulmonary function, thus this difference may be more susceptible to worsen the EELV in the not-ventilated group, which has not been observed. Moreover, because the choice to maintain or not ventilation during CPB was left to the discretion of the medical team, it may be a source of selection bias. Finally, we cannot rule out a lack of power related to the limited sample size.

\section{Conclusion}

The effects of maintaining mechanical ventilation during cardiopulmonary bypass are still controversial to this day. In our work, this strategy does not seem to allow a better preservation of FRC after cardiac surgery. However, our study has certain limitations, and a randomized controlled study is warranted to confirm or deny our results, notably focusing on complex cardiac procedures and on patients with pre-existing risk factors for pulmonary complications.

\section{Declarations}

Acknowledgments: We thank the "Fondation Charles Nicolle" for the financial support allowing the acquisition of the GE Carescape R860.

\section{Authors contributions}

LT: Writing original draft, investigation

NR: conceptualization, methodology, funding acquisition

VS, VW, FB, CA, JS, VC: Writing - review and editing

TC: Writing - review and editing, supervision 
EB: Writing original draft, investigation, supervision, methodology, formal analysis

\section{Ethics approval and consent to participate}

This study was approved by local ethics committee of the Rouen University Hospital under the approval number E2021-27 (chairperson, Pr Luc-Marie Joly). Because of the non-interventional design of the study, and according to the French law, no written consent was required.

\section{Consent for publication}

Not applicable

\section{Availability of data}

The datasets generated and/or analysed during the current study are not publicly available but are available from the corresponding author on reasonable request.

\section{Competing Interests}

The authors declare that they have no competing interests

\section{Funding}

No funding was required for this study

\section{References}

1. Szelkowski LA, Puri NK, Singh R, et al: Current trends in preoperative, intraoperative, and postoperative care of the adult cardiac surgery patient. Curr. Probl. Surg. 52:531-69, 2015

2. Weissman C: Pulmonary Complications After Cardiac Surgery. Semin. Cardiothorac. Vasc. Anesth. 8:185-211, 2004

3. Welsby IJ, Bennett-Guerrero E, Atwell D, et al: The Association of Complication Type with Mortality and Prolonged Stay After Cardiac Surgery with Cardiopulmonary Bypass: Anesth. Analg. 94:1072-8, 2002

4. Lindberg P, Gunnarsson L, Tokics L, et al: Atelectasis and lung function in the postoperative period. Acta Anaesthesiol. Scand. 36:546-53, 1992

5. Brismar B, Hedenstierna G, Lundquist H, et al: Pulmonary Densities during Anesthesia with Muscular Relaxation-A Proposal of Atelectasis: Anesthesiology 62:422-8, 1985

6. Fischer M-O, Courteille B, Guinot P-G, et al: Perioperative Ventilatory Management in Cardiac Surgery: A French Nationwide Survey. Medicine (Baltimore) 95:e2655, 2016

7. Passaroni AC, Silva MA de M, Yoshida WB: Cardiopulmonary bypass: development of John Gibbon's heart-lung machine. Rev. Bras. Cir. Cardiovasc. 2015 doi/10.5935/1678-9741.20150021

8. Loeckinger A, Kleinsasser A, Lindner $\mathrm{KH}$, et al: Continuous positive airway pressure at $10 \mathrm{~cm} \mathrm{H} 20$ during cardiopulmonary bypass improves postoperative gas exchange. Anesth. Analg. 91:522-7, 2000

9. Bignami E, Guarnieri M, Saglietti F, et al: Mechanical Ventilation During Cardiopulmonary Bypass. J. Cardiothorac. Vasc. Anesth. 30:1668-75, 2016

10. the PROVECS Study Group, Lagier D, Fischer F, et al: Effect of open-lung vs conventional perioperative ventilation strategies on postoperative pulmonary complications after on-pump cardiac surgery: the PROVECS randomized clinical trial. Intensive Care Med. 45:1401-12, 2019

11. Gattinoni L, Pesenti A: The concept of "baby lung." Intensive Care Med. 31:776-84, 2005

12. Matamis $D$, Lemaire F, Rieuf $P$ : Augmentation de la capacité résiduelle fonctionnelle induite par la ventilation en pression positive expiratoire. Prédiction par la courbe pression-volume thoracopulmonaire. Ann. Fr. Anesth. Réanimation 3:199- 
204,1984

13. Rylander C, Högman M, Perchiazzi G, et al: Functional Residual Capacity and Respiratory Mechanics as Indicators of Aeration and Collapse in Experimental Lung Injury: Anesth. Analg.:782-9, 2004

14. Toulouse E, Lafont B, Granier S, et al: French legal approach to patient consent in clinical research. Anaesth. Crit. Care Pain Med. 39:883-5, 2020

15. Olegård C, Söndergaard S, Houltz E, et al: Estimation of functional residual capacity at the bedside using standard monitoring equipment: a modified nitrogen washout/washin technique requiring a small change of the inspired oxygen fraction. Anesth. Analg. 101:206-12, table of contents, 2005

16. Chiumello D, Cressoni M, Chierichetti M, et al: Nitrogen washout/washin, helium dilution and computed tomography in the assessment of end expiratory lung volume. Crit. Care Lond. Engl. 12:R150, 2008

17. Dellamonica J, Lerolle N, Sargentini C, et al: Accuracy and precision of end-expiratory lung-volume measurements by automated nitrogen washout/washin technique in patients with acute respiratory distress syndrome. Crit. Care Lond. Engl. 15:R294, 2011

18. Berger-Estilita J, Haenggi M, Ott D, et al: Accuracy of the end-expiratory lung volume measured by the modified nitrogen washout/washin technique: a bench study. J. Transl. Med. 19:36, 2021

19. Ng CSH, Arifi AA, Wan S, et al: Ventilation During Cardiopulmonary Bypass: Impact on Cytokine Response and Cardiopulmonary Function. Ann. Thorac. Surg. 85:154-62, 2008

20. Futier E, Constantin J-M, Paugam-Burtz C, et al: A trial of intraoperative low-tidal-volume ventilation in abdominal surgery. N. Engl. J. Med. 369:428-37, 2013

21. Mercat A, Richard J-CM, Vielle B, et al: Positive end-expiratory pressure setting in adults with acute lung injury and acute respiratory distress syndrome: a randomized controlled trial. JAMA 299:646-55, 2008

22. Wang Y-C, Huang C-H, Tu Y-K: Effects of Positive Airway Pressure and Mechanical Ventilation of the Lungs During Cardiopulmonary Bypass on Pulmonary Adverse Events After Cardiac Surgery: A Systematic Review and Meta-Analysis. J. Cardiothorac. Vasc. Anesth. 32:748-59, 2018

23. Gibney BC, Wagner WL, Ysasi AB, et al: Structural and functional evidence for the scaffolding effect of alveolar blood vessels. Exp. Lung Res. 43:337-46, 2017

\section{Supplementary Files}

This is a list of supplementary files associated with this preprint. Click to download.

- SupplementaryFile1.jpg

- SupplementaryFile2.jpg

- SupplementaryFile3.docx 